\title{
IMPLEMENTATION OF SUMMATIVE ASSESSMENT IN PBL TUTORIALS: CULTURAL PERSPECTIVES
}

\author{
Umatul Khoiriyah*, Chris Roberts** \\ *Fakultas Kedokteran Universitas Islam Indonesia, Yogyakarta - INDONESIA \\ **Sydney Medical School The University of Sydney, Sydney - AUSTRALIA
}

\begin{abstract}
Background: Problem-based learning was developed firstly in western country which is dominated by western culture. The benefits of PBL implementaion in Eastern culture such as Asia have been studied. Many innovations have been developed to optimise the advantages of PBL on students learning in Asian countries. Faculty of Medicine Islamic University of Indonesia (FM IUI) has made an innovation by applying summative assessment in PBL tutorials. This study aims to evaluate the positive and negative effects of summative assessment in PBL tutorials based on a cultural perspective and to know whether this inovation could support students learning in PBL tutorials.

Method: The research was conducted qualitatively through semi-structure interview among 10 students and tutors of FM IUI, who have at least one year experience in PBL tutorials. Data was analysed thematically using Hofstede's cultural dimension.

Results: Ten themes that were distributed into 4 cultural dimensions were captured from the data. It consisted of Power distance ( 2 themes), uncertainty avoidance (3 themes), Individualism vs collectivism ( 2 themes), short orientation vs long orientation ( 2 themes). Summative assessment were able to stimulate student to participate actively in tutorial, to have willingness conducting self-improvement and the need of feedback from tutor. On the other hand, this assessment induced the students to be a score oriented. It also reduced group harmonisation. Supporting factors such as case design, tutor capability and students' understanding about PBL need to be considered.

Conclusion: Summative assessment in PBL tutorials has both positive and negative impacts on the quality of tutorial process. It could support students learning in some aspects, however; it also reduce the quality of tutorial process. To minimise the negative effects, supporting factors should be optimised. Faculty should also consider other innovations that are more appropriate with Eastern culture and PBL characteristics.
\end{abstract}

Keywords: summative assessment, PBL tutorials, Hofstede framework

\begin{abstract}
ABSTRAK
Latar belakang: Problem Based Learning adalah metode pembelajaran yang berasal dari negara barat. Kesesuaian metode tersebut untuk diilmpelementasikan di budaya Timur khususnya Asia masih terus dikaji. Berbagai inovasi dilakukan untuk mengoptimalkan implementasi dan manfaat PBL di institusi di wilayah Asia. Fakultas Kedokteran Universitas Islam Indonesia (FK UII) mengembangkan inovasi dengan melakukan penilaian sumatif pada proses diskusi tutorial. Penelitian ini bertujuan untuk mengevaluasi dampak positif dan negatif implementasi penilaian tutorial pada proses diskusi tutorial mahasiswa dengan menggunakan tinjauan kultural. Tujuan khusus untuk mengetahui kesesuaian metode penilaian tersebut dalam membantu mahasiswa mengimplementasikan metode PBL.

Metode: Penelitian dilakukan secara kualitatif menggunakan metode wawancara semi terstruktur kepada 10 mahasiswa dan 9 tutor di FK UII yang mempunyai pengalaman tutorial minimal 1 tahun. Data dianalisis secara tematik menggunakan perspektif kultural yang dikembangkan oleh Hofstede.
\end{abstract}

contact: umakhoiriyah@uii.ac.id 
Hasil: Sepuluh tema terangkum dari data peneltian, yang tersebar dalam 4 dimensi kultural Hofstede: Individualisme atau kolektivisme ( 3 tema),orientasi jangka pendek vs jangka panjang ( 2 tema), poower distance ( 2 tema) dan uncertainty avoidance (3 tema). Penilaian sumatif dapat menstimulasi keaktifan mengemukakan pendapat, kemampuan memperbaiki diri, dan kebutuhan feedback dari tutor. Disisi lain, penilaian tersebut menyebabkan mahasiswa lebih berorientasi ke nilai dan berkurangnya keharmonisan kelompok. Faktor pendukung seperti desain kasus, kapabilitas tutor dan kepahaman mahasiswa mengenai PBL perlu diperhatikan.

Kesimpulan: Penilaian sumatif pada proses diskusi tutorial dapat berefek positif maupun negatif pada kuaitas tutorial.Inovasi tersebut dalam beberapa aspek dapat membantu mahasiswa belajar di tutorial PBl. Namun di lain hal, inovasi tersebut menurunkan kualitas proses diskusi. Untuk meminimalkan dampak negatif tersebut, faktor pendukung perlu dioptimalkan oleh pihak fakultas dan atau dengan membuat inovasi yang lebih sesuai dengan karakterisitik PBL dan budaya Timur.

Kata kunci: penilaian sumatif, tutorial PBL, Hofstede framework

\section{PENDAHULUAN}

Problem Based Learning (PBL) merupakan western pedagogy yang telah diadopsi di berbagai negara di dunia termasuk negara-negara di Asia. ${ }^{1}$ Di Indonesia, hampir semua fakultas kedokteran telah mengadopsi PBL sebagai metode belajar utama. Implementasi PBL di negara-negara Asia, yang didasari pada budaya timur, memiliki tantangan yang berbeda jika dibandingkan dengan di negaranegara di Eropa. Faktor budaya berpengaruh terhadap karakteristik mahasiswa dan kegiatan belajar sehingga kualitas implementasi PBL di negara-negara Asia berbeda dengan di negara dengan budaya barat khususnya negara Eropa. ${ }^{2}$

Problem Based Learning dilaksanakan berdasar 4 prinsip pembelajaran yaitu konstruktif, kolaboratif, konteksual,danself-directed. ${ }^{3}$ Pembelajarankonstruktif merupakan pembelajaran yang dilaksanakan dengan memberikan kesempatan kepada mahasiswa untuk menyusun pengetahuannya sendiri. Dalam prinsip pembelajaran ini, tugas pendidik adalah memfasilitasi agar mahasiswa mempunyai pengalaman belajar yang cukup sehingga dapat digunakan untuk membangun pengetahuannya sendiri. Pembelajaran kolaboratif adalah pembelajaran yang dilaksanakan secara berkelompok yang memungkinkan para anggotanya untuk bertukar pendapat dan sharing pengetahuan untuk menyusun pengetahuan bersama. Dalam pembelajaran kolaboratif, terjadi proses elaborasi dan integrasi pendapat dari anggota kelompok sehigga kerjasama antara anggota tim sangat dibutuhkan. Prinsip pembelajaran yang ketiga adalah kontekstual yaitu kegiatan pembelajaran yang dilaksanakan dengan mengaitkan pengetahuan dengan konteks sehingga memudahkan transfer pengetahuan tersebut jika diaplikasikan pada konteks yang hampir sama atau ada kemiripan dengan konteks yang digunakan saat mempelajari pengetahuan tersebut. Prinsip pembelajaran yang ke-empat adalah self-directed learning. Pada prinsip pembelajaran ini mahasiswa diharapkan mempunyai kemandirian dalam mengelola kegiatan belajarnya yang meliputi proses perencanaan, monitoring pelaksanaan, implementasi berbagai strategi belajar dan evaluasi proses belajar. ${ }^{4}$

Implementasi keempat prinsip PBL tersebut dapat dilaksanakan dengan optimal pada lingkungan belajar yang mendukung seperti lingkungan belajar yang menitikberatkan pada kemandirian dan adanya equalitas antara dosen dan mahasiswa. ${ }^{5} \mathrm{Di}$ negara-negara Eropa, lingkungan belajar seperti yang disebutkan tidak sulit ditemukan karena sesuai dengan karakter budaya barat. Berdasar tinjauan Hofstede ${ }^{6}$ karakter sebuah budaya dapat ditinjau dari 5 dimensi yaitu : Power distance, uncertainty avoidance, individualisme vs kolektivisme, maskulin dan feminin serta orientasi jangka pendek vs jangka panjang.

- Power distance: Merupakan kondisi terkait ketidaksamaan kedudukan antar anggota dalam sebuah struktur masyarakat atau komunitas 
yang tercermin dari penerimaan anggota masyarakat yang mempunyai kedudukan sosial yang lebih rendah untuk menerima kondisi tersebut. Pada struktur sosial yang memiliki power distance yang lebar biasanya terdapat hirearki sosial dimana setiap anggota dalam komunitas tersebut memiliki posisi tertentu. Dalam kegiatan pembelajaran, hal tersebut tercermin dari kesejajaran atau kesenjangan hubungan dosen dan mahasiswa. ${ }^{6,7}$

- Uncertainty avoidance: Dimensi ini terkait kesiapan atau ketidaksiapan (penghindaran) terhadap sutu situasi yang tidak pasti. Pada masyarakat yang tinggal di lingkungan dengan budaya uncertainty avoidance yang rendah, cenderung dapat beradaptasi dan bersifat fleksibel terhadap tugas yang ada. Sedangkan budaya uncertainty avoidance yang tinggi membuat anggota di komunitas tersebut tidak nyaman pada situasi yang tidak diatur secara rigid sehingga cenderung menyukai aturanaturan tertulis. Implementasi dimensi budaya ini pada kegiatan belajar dapat terlihat pada kesiapan mahasiswa ketika dihadapkan pada kegiatan belajar yang kurang terstruktur. ${ }^{6,7}$

- Inividualis vs kolektivis: Merupakan cerminan tingkat integrasi seorang anggota masyarakat dalam kelompok atau grup. Pada lingkungan dengan budaya individualis, anggota masyarakat cenderung hanya memikirkan diri mereka sendiri dan keterikatan antar anggota masyarakat cukup rendah. Sebaliknya, budaya kolektifis menekankan pada kohesifitas dan harmonisasi antar anggota kelompok..$^{6,7}$

- Maskulin Vs feminin. Pada masyarakat dengan karakter budaya maskulin biasanya terdapat pembagian peran dan status yang jelas antara laki-laki dan perempuan. Sedangkan pada masyarakat yang mengacu budaya femninin, terdapat persamaan hak antara laki-laki dan perempuan. Keduanya mempunyai peran dan kemampuan yang sama dalam mencapai sesuatu.$^{6,7}$

- Orientasi jangka panjang vs orientasi jangka pendek. Orientasi jangka pendek merupakan orientasi yang memfokuskan untuk pengerjaan suatu hal pada suatu waktu yang ditentukan.
Sebaliknya, orang yang dibesarkan pada budaya yang beorientasi jangka panjang cenderung lebih fleksibel dalam pengaturan waktu dan perubahan rencana. Pada kegiatan pembelajaran, implementasi jenis orientasi ini akan berpengaruh terhadap ketahanan atau persisten mahasiswa terhadap kendala pembelajaran. ${ }^{6,7}$

Prinsip pembelajaran yang mendasari PBL akan dapat terlaksana secra optimal jika didukung oleh budaya yang sesuai dengan karakteristik PBL. Problem Based Learning membutuhkan lingkungan belajar dengan power distance yang kecil atau dekat karena PBL merupakan metode belajar yang bersifat student centered dengan hubungan dosen dan mahasiswa bersifat setara. Mahasiswa juga diharapkan dapat belajar secara mandiri dengan terbiasa belajar pada situasi yang tidak terstruktur dan tidak bergantung pada arahan dosen. Hal tersebut sesuai dengan sifat dari budaya dengan uncertainty avoidance yang rendah. Terkait dengan tingkat individualisme atau kolektivise, implemen, ltasi PBL membutuhkan budaya individualis maupun kolektivis. Pada diskusi tutorial PBL seorang mahasiswa diharapkan aktif sebagai individu untuk sharing pendapat. Perbedaan pedapat terkait pengetahuan yang disampaikan dapat terjadi di kelompok tutorial, namun harmonisasi kelompok harus dapat dijaga untuk mencapai tujuan belajar bersama. Selain itu, implementasi PBL cenderung membutuhkan karakter dengan budaya feminin dan orientasi jangka panjang. Mahasiswa diharapkan dapat melakukan adaptasi sosial dan melakukan semua prose pembelajaran dengan baik agar tercapai pemahaman dan hasil belajar yang optimal. ${ }^{5}$

Karakter budaya di Asia khususnya Indonesia adalah karakter budaya timur yang cukup berbeda dengan karakter yang menjadi ciri khas $\mathrm{PBL}^{5}$. Budaya timur bercirikan power distance yang lebar, tingkat uncertainty avoidance yang tinggi, kolektivis, dan cenderung maskulin., 5 Penelitian-penelitian yang ada menunjukkan adanya tantangan atau hambatan implementasi PBL di Asia yang disebabkan karena budaya tersebut, seperti hambatan terkait kemandirian mahasiswa atau 
terkait hubungan dosen dan mahasiswa. ${ }^{5,8}$ Upaya untuk mengoptimalkan implementasi PBL tersebut dilakukan dengan berbagai cara salah satunya dengan melaksanakan PBL sesuai dengan bahasa tutur di negara tersebut. ${ }^{1}$ Fakultas Kedokteran UII melakukan inovasi untuk meminimalisir hambatan budaya tersebut dengan mengimplementasikan penilaian sumatif pada diskusi tutorial PBL. Namun, belum pernah dilakukan evaluasi untuk menilai efektifitas inovasi tersebut. Penelitian ini bertujuan untuk mengidentifikasi dampak positif dan negatif implementasi penilaian sumatif pada proses diskusi tutorial mahasiswa, dengan menggunakan tinjauan kultural dan untuk mengetahui kesesuaian metode penilaian sumatif dalam membantu mahasiswa mengimplementasikan metode PBL.

\section{METODE}

Penelitian dilaksanakan dengan metode kualitatif dengan pendekatan studi kasus. Penelitian dilaksanakan di FK UII yang telah mengimplementasikan PBL sejak tahun 2001. Tutorial PBL di FK UII dilaksanakan dengan menggunakan metode Seven jump dari Maastricht. 9,10 Setiap kasus/ skenario diskusikan dalam 2-3 pertemuan dengan alokasi masing-masing pertemuan adalah 100 menit. Pada pertemuan pertama dilaksanakan langkah 1-5 seven jump, langkah ke 6 dilaksanakn secara mandiri oleh mahasiswa. Langkah ke-7 dilaksanakan pada pertemuan kedua dan ketiga.
Data penelitian dikumpulkan dengan cara wawancara semi terstruktur kepada 10 mahasiswa dan 9 tutor FK UII yang mempunyai pengalaman melaksanakan tutorial PBL minimal 1 tahun. Wawancara setiap responden berkisar antara 40 menit-90 menit. Data hasil wawancara di transkrip dan kemudian dianalisis menggunakan kerangka konsep 5 dimensi kultural dari Hofstede ${ }^{6,7}$ yaitu power distance, uncertainty avoidance, Individualis vs kolektivis, maskulin vs feminin. Data dianalisis secara tematik dengan tahap-tahap sebagai berikut $^{11}$ : 1) membaca secara berulang berulang transkrip penelitian untuk mengenal pola data dan mendapatkan ide awal, 2) melakukan koding awal dengan mengidentifikasi transkrip yang mempunyai makna dalam penelitian, 3) menentukan tema yang sesuai dengan mengelompokkan koding awal yang telah dibuat. 4) mereview kembali tema yang telah dibuat 5) membuat definisi dan memberikan nama pada tema yang sudah terbentuk. 6) membuat deskripsi data hasil penelitian

\section{HASIL DAN PEMBAHASAN}

Berdasarkan kategori 5 dimensi kulturan Hofstede, 10 tema (Tabel 1) teridentifikasi dari data penelitian dengan rincian sebagai berikut: Power distance (2 tema), uncertainty avoidance (3 tema), individualis vs kolektivis ( 2 tema), dan orientasi jangka panjang vs jangka pendek ( 3 tema), namun tidak ada tema yang termasuk kategori maskulin vs feminin.

Tabel 1. Hasil penelitian berdasar dimensi kultural Hofstede

\begin{tabular}{llc}
\multicolumn{1}{c}{ Dimensi kultural } & \multicolumn{1}{c}{ Tema penelitian } & $\begin{array}{c}\text { Dampak terhadap } \\
\text { kualitas tutorial PBL }\end{array}$ \\
Power distance & - Kesadaran kebutuhan feedback & + \\
& - Stigma tutor baik dan buruk terkait nilai & - \\
\hline Uncertainty avoidance & - Mengaplikasikan berbagai strategi belajar & $+/-$ \\
& - Kesadaran akan kebutuhan prior knowledge & + \\
\hline Individualis vs kolektivis & - Kebutuhan akan arahan tutor & $+/-$ \\
& - Stimulasi kompetisi & + \\
\hline Orientasi jangka pendek vs & - Motivasi untuk lebih giat belajar & - \\
\hline jangka panjang & - Harmonisasi kelompok berkurang & - \\
\hline
\end{tabular}




\section{Power distance}

Terkait faktor kultural power distance, implementasi penilaian sumatif pada tutorial PBL mempunyai dampak positif maupun negatif ( Tabel 1), dengan deskripsi secara rinci sebagai berikut:

\section{Kesadaran akan kebutuhan feedback}

Dampak positif implementasi model penilaian tersebut adalah terkait kesadaran mahasiswa akan kebutuhan feedback dari tutor. Mahasiswa berpersepsi bahwa penilaian sumatif pada tutorial PBL menjadikan mereka berusaha untuk memiliki performa terbaik saat tutorial. Mahasiswa merasakan bahwa masukan atau feedback dari tutor akan membantu untuk memperbaiki performa tutorialnya. Mahasiswa berharap tutor tidak hanya memberi masukan kepada performa kelompok secara umum, namun juga masukan terkait performa masing-masing mahasiswa sehingga mahasiswa mengetahui hal yang masih perlu perbaikan.

"... dilihat dari bantuan feedback dari tutor, itu juga salah satu untuk menilai mahasiswanya. Feedback selama ini menurut saya belum sesuai. Saya kan suka dinilai. Kalo misal ada tutor yang awalnya dia mem-feedback keseluruhan, kemudian mefeedback secara personal, lebih bantu dari belajarnya. Kamu kurang aktif, kamu menjelaskannya kayak gini. Kalo difeedback satusatu kan jadi introspeksi sehingga kedepannya lebih baik lagi" (Mahasiswa 8-P1).

Hasil penelitian tersebut menunjukkan inovasi penlaian sumatif membuat mahasiswa menyadari akan kebutuhan feedback dari tutor yang dapat dipergunakan untk perbaikan cara belajar. Feedback dari tutor tersebut dapat menstimulasi mahasiswa untuk mengaplikasikan self-regulated learning yang merupakan salah satu karakteristik yang dibutuhkan dalam PBL. ${ }^{2}$ Kesadaran akan kebutuhan feedback dari tutor tersebut juga dapat mengurangi adanya hierarki sosial sehingga mahasiswa tidak berpersepsi bahwa tutor adalah semata-mata sebagai sumber pengetahuan. ${ }^{5,8}$
Stigma tentang tutor yang baik

\section{dan yang kurang baik}

Penilaian sumatif di tutorial membuat mahasiswa mempunyai kriteria tersendiri tentang tutor yang baik dan tutor yang tidak disukai. Mahasiswa berpendapat bahwa tutor yang baik adalah tutor yang mudah dalam memberikan nilai bagus. Sedangkan tutor yang cenderung sulit dalam memberikan nilai, dianggap tutor yang tidak baik. Beberapa mahasiswa berpersepsi bahwa mereka kurang menyukai tutor yang sering mengarahkan proses diskusi atau memberikan stimulasi berupa pertaanyaan karena menyebabkan mahasiswa tidak bisa mengemukakan pendapat sesuai dengan yang mereka inginkan. Contoh pernyataan mahasiswa tersebut adalah sebagai berikut

"Tergantung tutornya, sebenarnya enak juga ya dapat tutor yang baik, nilainya murah itu membuat kayak mahasiswa itu semangat mencari bahannya yang kurang. Tapi kalo dapat tutor yang killer kita tu malah tidak enak mengekspresikan pendapat dari yang kita dapat. Misal kita lagi ngucapkan sesuatu, langsung ditanya sumbernya dari mana $d s b$, mending tidak usah ngomong deh..." (Mahasiswa 2-P2)

Stigma mahasiswa terhadap tutor yang baik dan yang kurang baik tersebut membuat hubungan mahasiswa dan tutor tidak seperti yang di harapkan dalam PBL. Mahasiswa menilai kualitas peran tutor berdasar hasil penilaian atau skor yang mereka peroleh dalam tutorial. Hasil penelitian ini sejalan dengan penelitian Frambach', yang menyatakan bahwa pada tatanan masyrakat dengan hierarki sosial yang cukup jelas seperti di Timur Tengah dan Asia, mahasiswa cenderung tidak menyukai tutor yang banyak bertanya atau memberikan stimulasi dalam tutorial.

\section{Uncertainty avoidance}

Dampak Penilaian sumatif pada tutorial jika ditinjau dari faktor kultural uncertainty avoidance (kecenderungan menghindari tugas yang belum jelas) dapat dikelompokkan menjadi 3 tema yaitu stimulasi untuk menerapkan berbagai strategi 
belajar, kesadaran akan kebutuhan prior knowldege dan kebutuhan akan arahan tutor. Dampak tersebut dapat berpengaruh positif maupun negatif pada impelementasi tutorial yang sesuai kaidah PBL (Tabel 1).

\section{Penerapan berbagai strategi belajar}

Dampak positif penilaian sumatif di tutorial PBL adalah dapat menstimulasi mahasiswa untuk melakukan berbagai upaya agar dapat memberikan performa terbaiknya saat diskusi. Upaya tersebut salah satunya dengan mengaplikasikan berbagai strategi belajar agar mahasiswa dapat melakukan sharing pengetahuan secara optimal. Strategi belajar yang diterapkan mahasiswa diantaranya adalah diskusi mandiri, dan diskusi dengan kakak kelas.

"Saya merasa lebih rajin dalam belajar, kalau misalnya tidak ada tutorial motivasi belajar mandiri tidak terlalu tinggi, karena tidak ada tuntutan untuk belajar rutin. Kalau tutorial dengan jadwal yang sudah pasti Senin, Rabu dan Jumat, minimal malam harinya atau pagi harinya harus belajar kalau mau mendapatkan hasil yang maskimal dalam tutorial, karena tutorial itu sendiri kan sumber nilai"(Mahasiswa1-A1).

Hasil penelitian tersebut sesuai dengan penelitian sebelumnya yang dilakukan oleh Cilliers ${ }^{12}$ yang mengungkapkan bahwa penilaian sumatif akan menstimulasi mahasiswa untuk melakukan berbagai upaya agar memperoleh hasil yang optimal. Implementasi berbagai strategi belajar yang diimplementasikan oleh mahasiswa dapat meminimalisir keluhan mahasiswa tentang ketidakjelasan tujuan belajar dalam metode PBL. Hasil penelitian sebelumnya menunjukkan bahwa mahasiswa dengan latar belakang budaya timur seperti Timur tengah dan Asia, mempunyai kesulitan mengimplementasikan PBL karena mereka harus menetapkan tujuan belajar sendiri dan ketidakjelasan materi yang harus dipelajari. ${ }^{1,4}$

\section{Kebutuhan prior knowledge}

Penilaian sumatif di tutorial menjadikan beberapa mahasiswa berusaha untuk bisa menunjukkan performa terbaik di setiap pertemuan tutorial, termasuk dipertemuan pertama yang dilaksanakan berdasar prior knowledge mahasiswa. Mahasiswa berharap kualitas diskusi yang ada tidak berbeda antara pertemuan pertama dengan pertemuan kedua yang dilaksanakan berdasar hasil belajar mandiri. Mahasiswa juga berharap kasus yang diskusikan sesuai dengan prior knowledge mereka, sehingga proses diskusi berjalan lancar dan mahasiswa mendapat nilai yang optimal. Beberapa mahasiswa mensiasati dengan membuat persiapan dan membuat catatan untuk diskusi pertemuan pertama seperti contoh pernyataan berikut:

"untuk brainstorming, kalo dulu awal-awal itu betul-betul sepemahaman kita jadi belum belajar banyak. Tapi di akhir tahun pertama (pada semester 2 dan 3) kebanyakan dari teman-teman sudah mempersiapkan. Jadi waktu brainstorming sekarang ini sudah lumayan dalam, sudah membawa catatan-catatan kecil dan semuanya hampir terbahas tapi masih superfisial.."( Mahasiswa 6-A2).

Hasil penelitian tersebut menunjukkan bahwa penilaian sumatif pada tutorial berdampak negatif pada proses diskusi mahasiswa. Proses brainstorming yang bertujuan untuk membantu mahasiswa mengidentifikasi kebutuhan belajar tidak berjalan dengan baik. ${ }^{3}$ Mahasiswa tidak optimal dalam mengaktifkan prior knowldge karena menggunakan catatan dalam pertemuan pertama tersebut. Hasil penelitian tersebut juga menunjukkan bahwa penialian sumatif tidak dapat meminimalisir kendala faktor budaya yaitu kecemasan untuk berkomunikasi apabila tidak mempunyai pengetahun atau prior knowledge yang cukup. ${ }^{8}$

\section{Kesadaran akan kebutuhan arahan dari tutor}

Data penelitian juga menunjukkan bahwa dalam proses diskusi tutorial mahasiswa berharap tutor dapat mengarahkan proses diskusi sesuai dengan tujuan belajar yang ditetapkan oleh fakultas. Mahasiswa berharap tutor dapat memberikan arahan apabila ada kesulitan dalam proses diskusi. Selain itu, tutor diharapkan juga bisa menjadi motivator sehingga mahasiswa tetap memiliki 
semangat untuk mencari infomasi secara mandiri. Namun, ada mahasiswa juga yang berpendapat bahwa tutor dalam memberi arahan harus bersifat detil terutama dalam memberi tahu jenis sumber informasi atau referensi yang dipergunakan selama proses diskusi tutorial seperti salah satu contoh pernyataan mahasiswa berikut:

Kalo bloking gitu sama tutor diarahin, kalian pernah gak baca yang ini. Coba kalo kalian baca ini, ini nanti tentang itu ada. Tentang ini tu harusnya begini-begini. Ya paling gak kalian belajar dikit lah tentang itu. Kadang suka cerita jug atentang pengalaman di RS, terus ngasih tahu bacaanya juga ( mahasiswa 3-A3)

Hasil penelitian tersebut menunjukkan bahwa kesadaran mahasiswa akan kebutuhan arahan tutor dapat berdamapak positif maupun negatif terhadap kualitas implementasi tutorial PBL. Dampak poisitifnya adalah mahasiswa semakin meyadari peran tutor dalam mengarahkan diskusi. Ketidakjelasan dalam proses diskusi dapat di bantu oleh tutor dengan arahan berupa pertanyaan stimulasi dan motivasi. Sedangkan dampak negatifnya adalah pada sebagian mahasiswa, tutor diharapkan bisa memberikan informais secara detil seperti yang juga ditemukan dalam penelitian sebelumnya ${ }^{4,8}$. Kondisi kebergantungan akan informasi dari tutor tidak hanya ditemukan pada tutorial dengan penilaian sumatif. Secara umum, mahasiswa yang tinggal di negara dengan budaya timur mempunyai pemikiran bahwa guru atau dosen merupakan sebagai sumber pengetahuan utama sehingga mereka kurang mempercayai informasi yang dijelaskan oleh temannya dalam diskusi. ${ }^{4,5,8}$

\section{Individualis Vs Kolektivis}

\section{Meningkatkan motivasi belajar}

Adanya penilaian sumatif meningkatkan motivasi belajar mahasiswa karena jika tidak melakukan persiapan sebelum tutorial atau tidak belajar dengan baik, mahasiswa tidak dapat berkontribusi untuk menyampaikan pendapat selama proses diskusi tutorial. Hal tersebut akan berefek pada rendahnya pencapaian diskusi tutorial.
“... ya masih semangat, tapi kalo tidak dinilai itu jadi kadang-kadang agak sedikit ditunda-tunda. Kalo dinilai itu kayak dikejar setoran, hari ini harus belajar. Planningnya harus bagus kalo dinilai.(Mahasiswa 7-IC2)

Tutor yang menjadi responden dalam penelitian ini juga memiliki pendapat yang sama bahwa impelementasipenilaiansumatiflebihmeningkatkan motivasi belajar mahasiswa daripada penilaian yang bersifat formatif yang lebih menekankan pada pemberian feedback untuk perbaikan mahasiswa. Tutor berpendapat hal tersebut terjadi karena mahasiswa belum memahami sepenuhnya tentang manfaat penilaian formatif " ....kalo keuntungannya sumatif , mahasiswa jadi terpacu karena itu akan menentukan nilai akhir. Ya karena budaya kita kan memang masih seperti itu."(Tutor 1-Ic 1).

Hasil penelitian ini menunjukkan bahwa penilaian sumatif dapat meningkatkan motivasi mahasiswa. Mahasiswa cenderung terstimulasi secara ekstrinsik untuk meningkatkan kualitas belajar karena ingin memperoleh nilai terbaik Penilaian sumatif mendoronng mahasiswa untuk belajar secara superfisial karena target utama mahasiswa bukan kepahaman melainkan capaian nilai. Sebaliknya penilaian formatif mendorong mahasiswa untuk menerapkan pendekatan belajar yang mendalam (deep learning approach). ${ }^{13}$ Dengan demikian, penilaian sumatif berdampak positif dalam meningkatkan motivasi belajar, namun dampak tersebut belum optimal karena tidak mendorong mahasiswa untuk memahami materi secara mendalam.

\section{Stimulasi iklim kompetisi}

Efek lain dari penilaian sumatif adalah timbulnya iklim kompetisi dalam proses diskusi tutorial. Masing-masing anggota kelompok berusaha untuk memperoleh nilai tutorial sebaik-baiknya dengan banyak menyampaikan pendapat selama tutorial. Setiap mahasiswa berusaha menunjukkan performa terbaiknya selama diskusi tutorial. Namun mahasiswa juga berpendapat bahwa ada beberpa mahasiswa yang mempunyai kecenderungan untuk terus menerus berkontribusi dalam proses diskusi 
tutorial tanpa memberi kesempatan anggota lain seperti yang diungkapkan oleh salah satu responden berikut:

“... suka gak suka ya itu teman kita dalam diskusi jadi harus diterima. Tapi saya paling gak suka sama orang yang gak tahu porsi. Misal dalam tutorial itu kan kita ber 11, kita masing-masing mencari nilai, dan dia terlalu menggebu-gebu mencari nilainya sendiri ". (Mahasiswa 7-IC1)

Iklim kompetisi yang muncul sebagai akibat penilaian sumatif pada tutorial dapat berdampak positif maupun negatif pada kualitas implementasi tutorial PBL. Efek positifnya adalah semua anggota berusaha untk berkontribusi dan tidak sungkan dalam mengemukakan pendapat. Hal ini dapat menstimulasi mahasiswa untuk mempunyai tipe komunikasi yang terbuka seperti yang dibutuhkan dalam PBL. Penelitian sebelumnya ${ }^{5,14}$ dan beberapa literatur ${ }^{1,15}$ menunjukkan bahwa mahasiswa Asia cenderung memiliki pola komunikasi tertutup atau cenderung enggan menyampaikan pendapat karena khawatir dianggap bodoh atau tidak tahu. Namun, iklim kompetisi dalam tutorial tersebut dapat menyebabkan efek yang tidak diharapkan yaitu kualitas diskusi menjadi superfisial dan tidak sesuai dengan tujuan belajar yang diharapkan fakultas. Mahasiswa aktif menyampaikan pendapat karena berorientasi pada prestasi.

\section{Berkurangnya harmonisasi kelompok}

Hasil penelitian juga menunjukkan bahwa beberapa mahasiswa terlalu mendominasi dalam proses diskusi tutorial karena ingin mendapatkan nilai tutorial seoptimal mungkin. Hal tersebut dapat menyebabkan harmonisasi dalam kelompok berkurang (Tabel 1). Mahasiswa berpendapat bahwa sebagian rekan-rekannya yang berebut untuk menyampaikan pendapat selama proses diskusi, bertujuan bukan karena ingin mencapai tujuan belajar bersama namun untuk mendapatkan nilai. Mahasiswa tersebut cenderung tidak menghargai pendapat dan tidak memberi kesempatan anggota kelompok yang lain.

"... jadi kita tu kayak sikut-sikutan sama teman tu "aku banyakin ngomong" jadi kadang-kadang muncul keegoisan sendiri. Jadi sebatas cari nilai bukan untuk sharing cerita. Jadi hanya untuk mengejar nilai. Itu gak sukanya kayak gitu". (Mahasiswa 3-IC3)

Harmonisasi kelompok adalah salah satu ciri utama budaya timur yang selaras dengan karakteristik pembelajaran kolaboratif pada $\mathrm{PBL}^{8}$. Setiap anggota kelompok diharapkan dapat bekerjasama menyusun pengetahuan dan bertoleransi untuk mencapai tujuan belajar bersama ${ }^{2}$. Adanya penilaian sumatif menyebabkan harmonisasi kelompok berkurang karena masing-masing anggota cenderung menunjukkan dirinya untk mendampatkan nilai terbaik. Hal tersebut sangat berbeda dengan karakter budaya timur yang cenderung menjaga keharmonisan antar anggota grup. ${ }^{8,15}$

\section{Orientasi jangka pendek Vs jangka panjang Berorientasi nilai}

Implementasi penilaian sumatif pada diskusi tutorial memberikan dampak kepada sebagian besar mahasiswa. Mereka belajar dengan orientasi untuk mendapatkan nilai tutorial yang baik. Sebagian besar mahasiswa berusaha menunjukkan kemampuan masing-masing dengan aktif menyampaikan pendapat walaupun hanya sekedar membaca buku. Mahasiswa berusaha menunjukkan performa tutorial sesuai dengan aspek yang dinilai di form penilaian tutorial seperti peran aktif dan komunikasi.

“... Kalo menurut saya karena sistem nilai Saya merasa orientasi teman-teman itu bukan belajar, tapi mereka mencari bagaimana nilai itu setinggitingginya untuk Show up. Saya tahu itu. Mereka takut dianggap tidak tahu" (Mahasiswa 5-O2)

Pernyataan mahasiswa tersebut sejalan dengan yang disampaikan oleh tutor yang menjadi responden penelitian. Mahasiswa cenderung berusaha untuk aktif menyampaikan pendapat dengan tujuan untuk mendapatkan nilai tutorial terbaik. Namun seringkali pendapat yang disampaikan mahasiswa tersebut kurang berkualitas karena mahasiswa hanya sekedar membaca tanpa berusaha menjelaskan dengan bahasa sendiri dan tidak 
menganalisis informasi yang disampaikan tersebut. Hasil penelitian ini selaras dengan penelitian sebelumnya yang menunjukkan bahwa penilaian sumatif mendorong mahasiswa untuk belajar secara superfisial dan tidak memahami materi dengan baik. Mahasiswa cenderung berpikir pragmatis. ${ }^{13}$

\section{Perbaikan diri}

Selain berdampak menjadikan sebagian besar mahasiswa belajar berorientasi pada nilai, penilaian sumatif juga mempunyai efek yang terkait orientasi jangka panjang mahasiswa yang cenderung bersifat positif. Beberapa mahasiswa berpendapat bahwa hasil penilaian tutorial dapat menjadi salah satu sumber masukan atau informasi untuk mengetahui kelebihan dan kekurangan mereka dalam melaksanakan tutorial. Informasi tersebut dijadikan dasar untuk memperbaiki strategi belajar dan performa dalam diskusi tutorial.

"... Mungkin pernah satu blok, 2 blok yang saya merasa sudah maksimal tapi ternyata nilainya belum baik. Saat itu coba saya ingat-ingat tutorial saya gimana, mungkin ada satu dua pertemuan yang memang kurang maksimal.(Mahasiswa 1-O1)".

Skor atau capaian nilai dapat menjadi sarana penilaian diri atau self-assessment mahasiswa dengan cara membandingkan performanya dengan performa yang dikehendaki oleh fakultas atau dengan performa temannya ${ }^{16}$. Hasil penelitian menunjukkan bahwa capaian nilai tutorial mahasiswa dapat menjadikan sarana bagi mahasiswa untuk menilai kelebihan dan kekurangannya dalam berdiskusi. Hasil ini sejalan dengan penelitian sebelumnya yang menunjukkan bahwa penilaian sumatif dapat berdampak jangka pendek ,seperti orientasi nilai yang dipaparkan di tema sebelumnya, maupun orientasi jangka panjang yang terkait kemampuan untuk mengevaluasi kapabilitas diri (self-efficacy). ${ }^{12}$

\section{Faktor pendukung}

Mahasiswa dan Tutor yang menjadi responden penelitian berpendapat bahwa implementasi penilaian sumatif di diskusi tutorial akan memberikan manfaat yang optimal untuk belajar mahasiswa jika didukun oleh beberapa faktor seperti 1) kepahaman mahasiswa tentang PBL. 2) kemampuan tutor dalam mengarahkan diskusi 3) kualitas kasus/ skenario yang digunakan sebagai pemicu dalam diskusi.

\section{Kepahaman mahasiswa tentang PBL}

Kepahaman mahasiswa tentang PBL akan menunjang pelaksanaan diskusi tutorial. Tutor berpersepsi jika mahasiswa mempunyai kepahaman yang baik tentang PBL, mahasiswa akan dapat berdiskusi sesuai kaidah untuk mencapai tujuan belajar dan tidak hanya berorientasi nilai tutorial. Dengan kepahaman tersebut, kemandirian belajar dan tanggung mahasiswa juga akan terbentuk dengan baik. Untuk membentuk kepahaman tentang pembelajaran yang berpusat pada mahasiswa, perlu dilakukan usaha khusus dari fakultas karena pola pembelajaran mahasiswa saat di bangku pendidikan sebelumnya masih menggunakan metode pembelajaran konvensional.

"Mungkin yang paling mendasar yang saya pikirkan adalah budaya kita juga. Saya tidak tahu sih kalo anak SMA zaman sekarang, kalo zaman SMA kita dulu kan tidak diberi tanggung jawab - Jadi selama ini mahasiswa kita pun seperti itu. Jadi dia masuk atau datang kuliah mau jadi dokter tu..pikirnya "saya tu mau diberi sesuatu, bukan mau mencari sesuatu". Itu mungkin yang melatar belakangi.Ya..karena kalo kuliah konvensional kuliah datang dikasih ini." (Tutor 3-PM).

Hasil penelitian ini menunjukkan bahwa implementasi penilaian sumatif akan berdampak positif pada peningkatan kualitas tutorial PBL jika mahasiswa mempunyai kepahaman yang baik tentang metode PBL. Kepahaman tersebut ditunjang salah satunya oleh pengalaman belajar di bangku sekolah menengah yang merupakan salah satu faktor yang bersifat kontekstual yang dapat meminimalisir faktor-faktor kultural yang kurang mendukung implementasi PBL. ${ }^{8}$ Kepahaman tentang PBL sangat penting karena dapat mempengaruhi persepsi mahasiswa tentang cara belajar yang ideal, yang pada akhirnya akan berpengaruh pada performa tutorial mahasiswa. ${ }^{17}$ 


\section{Kualitas skenario/problem}

Selain kepahaman mahasiswa tentang PBL, kualitas skenarioatau kasus diskusi juga berpengaruh terhadap kualitas diskusi mahasiswa. Responden berpendapat bahwa kasus yang didesain dengan bagus dan relevan dengan konteks pekerjaan dokter, akan memotivasi mahasiswa untuk berdiskusi berdasar kasus tersebut. Mahasiswa akan tertarik untuk menganalisis kasus tersebut sehingga tidak hanya berorientasi untuk mendapatkan nilai tutorial yang baik.

"Sebenarnya kalo itu, skenarionya bagus, mahasiswa mampu memanfaatkan skenario , mereka bisa mengembangkan berpikir kritisnya" (Tutor 5-PK).

Hasill penelitian tersebut menunjukkan bahwa kualitas diskusitutorial salah satunya dipengaruhioleh kualitas problem diskusi. Problem / kasus diskusi yang baik adalah yang sesuai dengan karaktersitik PBl yang meruapakan pembelajaran yang bersifak konstruktif, kolaboratif, kontekstual dan self-directed. ${ }^{18}$ Kasus yang disusun hendaknya dapat memfasilitasi mahasiswa untuk mengintegrasikan pengetahuan lama dan pengetahuan baru, menstimulasi diskusi kelompok, dan sesuai dengan kodisi yang akan dihadapai saat menjadi dokter. Kasus diskusi juga idealnya dapat mendorong mahasiswa untuk mengidentifikasi kebutuhan belajarnya, menstimulasi belajar mandiri serta penggunaan berbagai media belajar. ${ }^{3,18}$ Dengan demikian, jika kasus diskusi didesain dengan baik, mahasiswa diharapkan mempunyai ketertarikan untuk mendalami kasus tersebut dan tidak hanya belajar karena berorientasi nilai.

\section{Kemampuan Tutor}

Faktor yang mendukung kualitas diskusi tutorial yang lain adalah kemampuan tutor dalam mengarahkan diskusi dan memotivasi mahasiswa. Mahasiswa berpendapat bahwa sebaiknya tutor dapat mengarahkan diskusi dengan baik dan bisa menjadi motivator.

"menurut saya tutor itu juga harus bisa bagaimana dia bisa menengahi dan mentriger. Menengahi dalam artian ketika diskusinya banyak beda pendapat. Misal ditutorial saya, ada teman yang menyampaikan pendapatnya seperti ini dari ini, dan satu lagi dari sana. Nah disana seharusnya bisa membantu mana data yang kita pakai atau tutor bisa mengatakan bahwa dua-duanya benar" (Mahasiswa 5-PT).

Pendapat mahasiswa tersebut sesuai dengan karakteristik tutor ideal dalam tutorial PBL. Tutor seharusnya dapat menstimulasi setiap anggota kelompok untuk secara aktif dapat menyampaikan pendapatatau pengetahuannya. Tutor hedaknyajuga dapat menstimulasi mahasiswa untuk menentukan tujuan belajar sendiri dan menggunakan sumber referensi yang valid. ${ }^{19}$ Kemampuan tutor untuk menstimulasi mahasiswa agar dapat aktif berkolaborasi dan menjadi pembelajar mandiri, akan berpengaruh pada kualitas tutorial mahasiswa ${ }^{2}$. Apabila tutor dapat mengarahkan diskusi dengan baik, setiap mahasiswa mempunyai kesempatan yang sama untuk berkontribusi sehingga dampak negatif penilaian sumatif pada tutorial seperti iklim kompetisi dan berkurangnya harmonisasi kelompok dapat diminimalisir

\section{KESIMPULAN}

Jika ditinjau dari aspek kultural, implementasi penilaian sumatif pada tutorial PBL mempunyai dampak positif maupun negatif dalam menunjang kualitas diskusi. Dampak positif inovasi penilaian tersebut adalah timbulnya kesadaran mahasiswa akan kebutuhan feedback dari tutor, peningkatan motivasi belajar dan menjadikan nilai tutorial untuk sarana perbaikan diri. Sebaliknya, dampak negatif metode penilaian tersebut adalah adanya stigma tutor yang baik dan buruk, kesadaran akan kebutuhan prior knowledge yang menjadikan proses diskusi tidak sesuai kaidah, dan berkurangya harmonisasi kelompok. Selain dampak positif dan negatif tersebut, ada beberapa dampak yang mempunyai dua efek sekaligus baik positif maupun negatif seperti kebutuhan akan arahan tutor, implementasi berbagai strategi belajar, dan adanya iklim kompetisi. Berbagai efek negatif implementasi penilaian sumatif tersebut dapat diminimalisir dengan memberikan kepahaman mahasiswa tentang PBL, menyusun kasus atau skenario sesuai kaidah dan kemmapuan tutor dalam mengarahkan 
diskusi. Upaya-upaya tersebut merupakan faktor pendukung yang jika dioptimalkan untuk meningkatkan kualitas tutorial PBL. Selain faktor pendukung, aspek lain yang dapat diperhatikan adalah melakukan inovasi yang sesuai dengan karakteristik PBL dan kultur budaya timur karena implementasi penilaian sumatif teridentifikasi menimbulkan efek negatif yang cukup banyak. Salah satu inovasi yang dapat menjadi alternatif adalah mengoptimalkan penilaian formatif agar mahasiswa dapat belajar secara mendalam dalam tutorial PBL.

\section{UCAPAN TERIMAKASIH}

Terimakasih kepada Tutor dan Mahasiswa FK UII yang telah bersedia menjadi responden pada penalitian ini.

\section{KETERANGAN}

Penelitian ini telah dipresentasikan di Seminar Just In Time (Jogja Rezndevous for Innovation and Transformation in Medical Education), Mei 2017.

\section{REFERENSI}

1. Choon-Eng Gwee M. Globalization of Problembased Learning (PBL): Cross-cultural Implications. Kaohsiung Journal of Medical Sciences. 2008; 24(3): S14-S22.

2. Frambach JM, Driessen EW, Chan L-C, van der Vleuten CPM. Rethinking the globalisation of problem-based learning: how culture challenges self-directed learning. Medical Education. 2012; 46(8): 738-47.

3. Dolmans D, Schmidt HG. The problem-based learning process. In: Van Berkel HJM, Scherpbier H, Hillen H, Van der Vleuten C, editors. Lessons from problem-based learning. New York: Oxford University Press; 2010.

4. Schmidt HG. Problem-based learning: An introduction. Instructional Science. 1994:22(4):247-50.

5. Choi I, Tae-Lee J, Rhee BD, Ju H. Challenges Experienced by Korean Medical Students and Tutors During Problem-Based Learning: A Cultural Perspective. Interdisciplinary Journal of ProblemBased Learning. 2016;10(1).

6. Hofstede G. Culture's consequences: Comparing values, behaviors, institutions and organizations across nations. Thousands Oak CA: Sage publications; 2003.

7. Hofstede G. Dimensionalizing Cultures: The Hofstede Model in Context. Online Readings in Psychology and Culture. 2011; 2(1).

8. Frambach JM, Driessen EW, Beh P, van der Vleuten CPM. Quiet or questioning? Students' discussion behaviors in student-centered education across cultures. Studies in Higher Education. 2014;39(6):1001-21.

9. Davis MH, Harden RM. AMEE Medical Education Guide No. 15: Problem-based learning: a practical guide. Medical Teacher. 1999;21(2):130-40.

10. Schmidt HG. Problem-based learning: rationale and description. Medical education. 1983;17(1):11-6.

11. Braun V, Clarke V. Using thematic analysis in psychology. Qual Res Psychol. 2006; 3(2): 77 -101.

12. Cilliers FJ, Schuwirth LW, Adendorff HJ, Herman $\mathrm{N}$, van der Vleuten CP. The mechanism of impact of summative assessment on medical students' learning. Advances In Health Sciences Education: Theory And Practice. 2010; 15(5): 695-715.

13. Al-Kadri HM, Al-Moamary MS, Roberts C, Van der Vleuten CPM. Exploring assessment factors contributing to students' study strategies: literature review. Medical Teacher. 2012; 34 (Suppl 1): S42-S50.

14. Khoo HE. Implementation of problem-based learning in Asian medical schools and students' perceptions of their experience. Medical Education. 2003; 37(5): 401-9.

15. Smith $\mathrm{PB}$. Communication styles as dimensions of national culture. Journal of Cross-Cultural Psychology. 2011; 42(2): 216-33.

16. Andrade $\mathrm{H}$, Valtcheva A. Promoting learning and achievement through self-assessement. Theory Into Practice. 2009; 48(1): 12-9.

17. Loyens SMM, Rikers, RMJ, \& Schmidt HG. Relationships between students' conceptions of constructivist learning and their regulation and processing strategies. Instructional Science. 2008; 36(5/6): 445-62.

18. Dolmans DHJM, Snellen-Balendong H, van der Vleuten CPM. Seven principles of effective case design for a problem-based curriculum. Medical teacher. 1997; 19(3): 185-9.

19. Moust JHC. The role of tutor. In: Berkel HJMV, Scherpbier H, Hillen H, Van der Vleuten C, editors. Lessons from problem-based learning. Oxford: Oxford University Press; 2010. 